\title{
Ampulla of Vater Neuroendocrine Tumor
}

National Cancer Institute

\section{Source}

National Cancer Institute. Ampulla of Vater Neuroendocrine Tumor. NCI Thesaurus.

Code C95981.

A well differentiated, low or intermediate grade tumor with neuroendocrine

differentiation that arises from the ampulla of Vater and periampullary region. 